\title{
CHRONIC COLD EXPOSURE: A WHITE ADIPOSE TISSUE BROWNING FACTOR
}

\author{
Martina Kitanova and Peter Ghenev \\ Department of General and Clinical Pathology, Medical University, Varna, Bulgaria
}

In the human body, there are two major subtypes of adipose tissue, white adipose tissue (WAT) and brown adipose tissue (BAT). Using ${ }^{18} \mathrm{~F}$-fluorodeoxyglucose (FDG), an intravenously administered radioactive glucose analog, it was demonstrated with positron emission tomography and computed tomography that the main BAT depots were disseminated throughout the human body (around the thoracic aorta, common carotid artery, brachiocephalic brachiocephalic artery, kidney, adrenal glands, liver, pancreas; in anterior mediastinum, supraclavicular fossa, axilla and thoracic paravertebral loci, also between neck muscles). The magnitude of FDG uptake by BAT was reported to increase with exposure to low temperature (1-4), hence cold exposure being considered one of the major browning factors (the myokine and adipokine irisin as well as other browning factors are not in the scope of present Dance Round).

While WAT stores lipids, BAT has the ability to increase energy expenditure realized by uncoupling respiration from ATP synthesis realized by uncoupling protein 1 . The knowledge about WAT and BAT were enriched with their two phenotypic expressions, namely brite (brown in white) and bruscle (brown in skeletal muscle) adipocytes (5-7). Brite (also known as beige) adipocytes sporadically reside within white WAT and emerge in response to certain environmental cues, such as chronic cold exposure, exercise, long-term treatment with PPAR $\gamma$ agonists (e.g., rosiglitazone) (8-10). This process is known as "browning" of WAT. Beige adipocytes are disseminated throughout the human body (in the cervical, supraclavicular, axillary, paraverte- bral regions, around epicardial coronary artery). Taken together, brown adipobiology became a challenge in the current biomedical research (1-11).

We report an autopsy case of a 66-year-old man who died during the winter from chronic heart failure exacerbated by bilateral pneumonia. He had been homeless for the last years so he had been chronically exposed to cold weather, especially during the last months of his life.

Intriguingly, histological examination of routinely processed sections of organs, revealed some unusual findings of the adipose tissue. First, substantial amount of multilocular, that is, brown/ brite, adipocytes were present in greater amount in their usual location, including around adrenal glands (Fig. 1). Next, besides their typical localization they were also found scattered in the subepicardial adipose tissue (Fig. 2) and intramyocardially (Fig. 3).

The described appearance of periadrenal, epicardial and intramyocardial adipose tissue inevitably elicited subsequent question: What is the reason for these uncommon findings in this case? All we knew for the patient was that he had been homeless and he died in the middle of the winter. Similar findings occur in mice subjected to intermittent cold exposure (11). These facts are tempting to suggest that in our case, it was the chronic cold exposure that triggered both expansion of BAT and browning of WAT.

\section{Conflict of interest}

The authors declare no conflict of interest. 


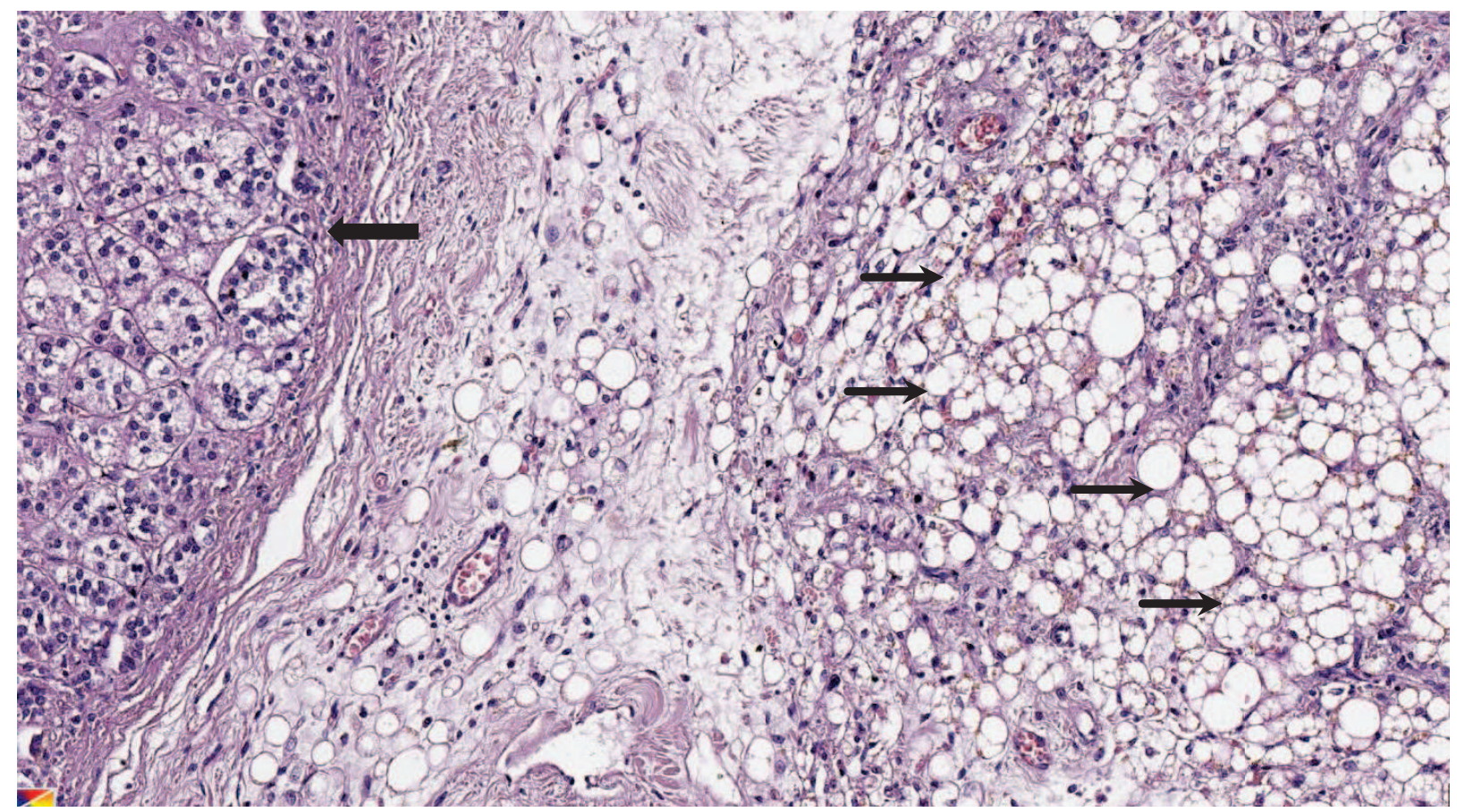

Figure 1. Adrenal gland (thick arrow), expansion of periadrenal brown (multilocular) adipocytes (arrows). Haematoxylin and eosin staining. Original magnification x100.

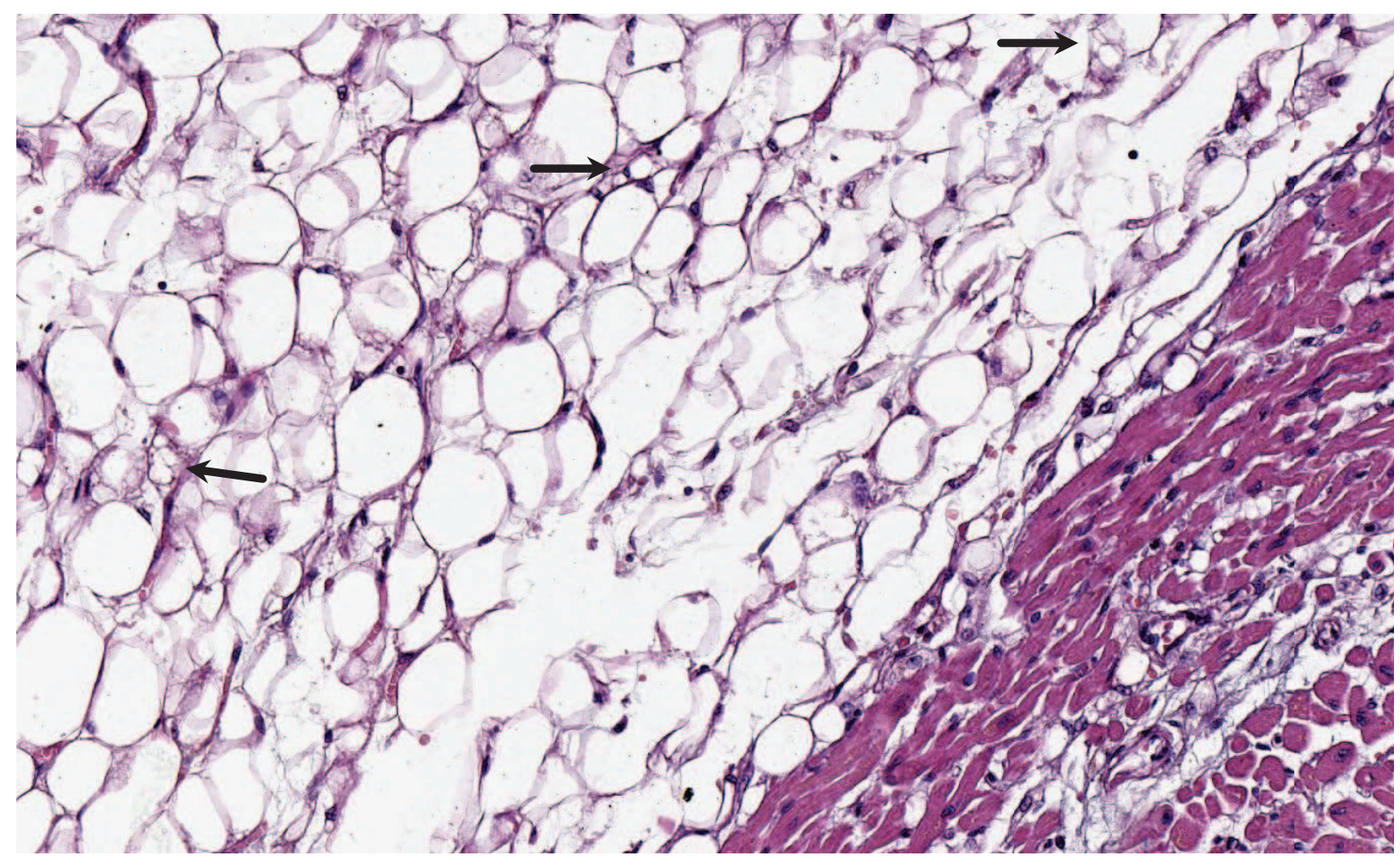

Figure 2. Subepicardial adipose tissue, scattered single or grouped multilocular (brown) adipocytes (arrows). Haematoxylin and eosin staining. Original magnification x200. 


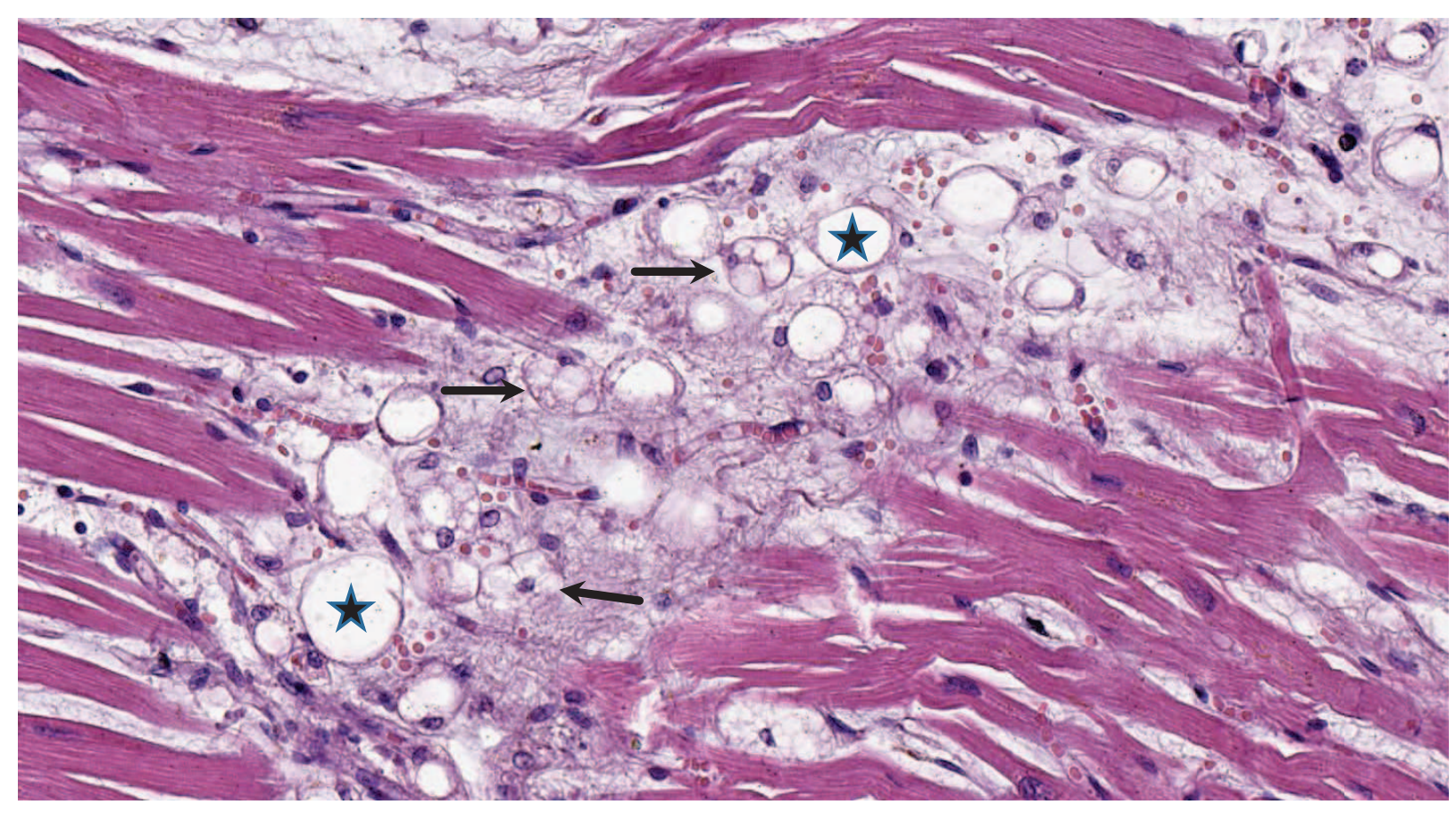

Figure 3. Intermingled unilocular (asterix) and multilocular (arrows) adipocytes among cardiomyocytes. Haematoxylin and eosin staining. Original magnification x200.

\section{References}

1. Sacks H, Symonds ME. Anatomical locations of human brown adipose tissue functional relevance and implications in obesity and type 2 diabetes. Diabetes 2013; 62: 1783-1790. [DOI: $10.2337 / \mathrm{db} 12-1430$ ]

2. Chechi K, Nedergaard J, Richard D. Brown adipose tissue as an anti-obesity tissue in humans. Obes Rev 2013; 15:92106. [DOI: 10.1111/obr.12116]

3. Chechi K, Carpentier AC, Richard D. Understanding the brown adipocyte as a contributor to energy homeostasis. Trends Endocrinol Metab 2013; 28: 408-420. [DOI: http:// dx.doi.org/10.1016/j.tem.2013.04.002]

4. Chechi K, Richard D. Thermogenic potential and physiological relevance of human epicardial adipose tissue. Int J Obes Supp Relat Metab Disord 2015; 5: S28-S34. [DOI: 10.1038/ijosup.2015.8]

5. Giralt M, Villarrova F. White, brown, beige/brite: different adipose cells for different functions? Endocrinology 2013; 154: 2992-3000. [PMID: 23782940]

6. Lidell ME, Matthias JB, Enerbäck S. Two types of brown adipose tissue in humans. Adipocyte 2014; 3: 63-66. [DOI:10.4161/adip.26896]
7. Harms M, Seale P. Brown and beige fat: development, function and therapeutic potential. Nat Med 2013;19:1252-1263. [PMID: 24100998]

8. Wu J, Cohen P, Spiegelman BM. Adaptive thermogenesis in adipocytes: is beige the new brown? Genes Dev 2013; 27:234-250. [DOI: 10.1101/gad.211649.112]

9. Symonds ME, K. Henderson, L. Elvidge, et al. Thermal imaging to assess age-related changes of skin temperature within the supraclavicular region co-locating with brown adipose tissue in healthy children. J Pediatrics 2012; 161: 892-898. [DOI: 10.1016/j.jpeds.2012.04.056]

10. Kajimura S, Saito M. A new era in brown adipose tissue biology: molecular control of brown fat development and energy homeostasis. Annu Rev Physiol 2014; 76:225-249. [DOI: 10.1146/annurev-physiol-021113-170252]

11. Yoo HS, Qiao L, Bosco C, Leong LH, Lytle N, Feng GS, et al. Intermittent cold exposure enhances fat accumulation in mice. PloS One 2014; 9(5): e96432. [DOI: 10.1371/journal. pone.0096432] 